\title{
ENTRE LA ESTATIVIDAD Y EL DINAMISMO: LOS ESQUEMAS CON QUEDAR EN GALLEGO
}

\author{
Between statics and dynamism: \\ Structures with quedar in the Galicien language
}

\author{
Xosé Soto Andión*
}

\section{PREÁmbulo}

Las construcciones intransitivas del gallego actual son objeto de nuestras investigaciones desde hace algunos años. Realizamos sobre ellas un trabajo de carácter descriptivo-analítico, con base empírica, desde una óptica de preferencia funcional. Al mismo tiempo pretendemos contrastar nuestros datos con los resultados de otras lenguas romances próximas. Este artículo se centra en las construcciones con quedar, verbo que funciona como predicado de una serie de esquemas semántico-sintácticos de una gran riqueza y variedad en esta lengua.

\section{INTRODUCCIÓN}

El trabajo que presentamos tiene como base las investigaciones realizadas para nuestra tesis doctoral, centrada en los esquemas semánticosintácticos de carácter intransitivo y en la elaboración de un diccionario analítico de construcciones para la lengua gallega. Este artículo aborda las construcciones intransitivas nucleadas por quedar. Muy pocos estudios, ninguno en gallego, han tenido como centro de análisis estas ricas y variadas construcciones, que están en el lenguaje cotidiano de casi todos los usuarios para satisfacer las necesidades comunicativas más variadas y que a menudo son consideradas construcciones de estado en función del significado primario que manifiesta el propio verbo. Nosotros tomando como base de análisis la teoría de la construcción pretendemos demostrar que las estructuras nucleadas por este predicado van más allá del valor de estado.

* Universidade de Vigo. 
Los resultados obtenidos pretenden ser de utilidad para posteriores trabajos de carácter contrastivo y/o comparativo así como para la elaboración de diccionarios convencionales y de construcciones, además de aportar información relevante tanto para la lingüística teórica en lo referente a establecer presupuestos universales derivados de los hechos particulares que se manifiestan en las distintas lenguas del mundo ${ }^{1}$ como para la lingüística contrastiva en lo relativo a comparación y contraste de lenguas. Las posibles equivalencias y/o divergencias con otras lenguas romances próximas son también de nuestro interés.

\section{CONTRUCCIONES INTRANSITIVAS VERSUS TRANSITIVAS}

A pesar de que gallego, portugués, castellano, italiano... son lenguas de tipo acusativo, fértiles en construcciones transitivas, la intransitividad como noción teórica y las construcciones intransitivas como actualización de esa noción juegan un papel fundamental a la hora de conceptualizar los hablantes la realidad a través de la lengua. Si bien la transitividad ha sido objeto de múltiples trabajos, la intransitividad como tal no genera demasiados estudios monográficos.

En la tradición gramatical, la intransitividad aparece caracterizada como un fenómeno inherente a una determinada clase de verbos, sobre todo los denominados "intransitivos", "intransitivos por naturaleza" y en ocasiones los "transitivos sin complemento directo". En relación con el hecho de considerar la intransitividad como propiedad de los verbos, conviene remarcar que para nosotros los verbos no son de suyo intransitivos ni transitivos, lo son las construcciones, por eso un verbo como chover (esp. llover) lo tratamos como un predicado de construcción intransitiva y no como un verbo intransitivo. Por tanto, la intransitividad la situamos no en el nivel de las clases de palabra sino en el de la construcción. En nuestra opinión esto debería reflejarlo también el diccionario en sus entradas. En cuanto a los llamados por la tradición verbos transitivos sin complemento directo como pintar, ler, escribir, beber... forman en realidad dos tipos de construcciones, una intransitiva y otra transitiva. La primera se produce cuando el verbo adquiere un significado pleno y designa caracterización del sujeto, hábito, manifestando también valor aspectual atélico (vgr. María pinta ${ }^{\circledR}$ María é pintora; María bebe ${ }^{\circ}$ María ten o hábito de beber). La segunda la tenemos en aquellas construcciones que reflejan una actividad ocasional y valor aspectual télico, con un complemento directo y un papel semántico de objeto / afectado / resultado, muy latente y deducible del contexto (vgr. limpou [a casa], pintou [algo] e preparou a comida).

\footnotetext{
${ }^{1}$ En palabras de Martinet (1993, p. 15-16) "Interesan las lenguas, todas las lenguas, en si mismas y por si mismas [...] desde que hay un interés por las lenguas en general, se tiende a proceder por inducción, es decir, a sacar conclusiones generales a partir de la existencia de ciertos hechos en las lenguas estudiadas".
} 
El fenómeno de la intransitividad generalmente se limita a un compartimento estanco, el de los verbos intransitivos o transitivos sin compl. directo frente al de los verbos transitivos, y diferenciada del ámbito de las construcciones ceroargumentales (neva, chove [esp. nieva, llueve]), pronominales, impersonales, atributivas y pasivas, que también se pueden llegar a intransitivizar (GIVON, 1990, p. 552; DIXON; AIKHENVALD, 2000), y que pueden ser calificadas como construcciones intransitivas.

Observamos que los conceptos de transitividad e intransitividad se manejan en muchas ocasiones asociados al significado etimológico de la palabra transitivo (< TRANSIRE, idea de paso o tránsito hacia otra entidad y por tanto a la idea de que en el verbo se expresa una acción que va más allá de él, hacia otro argumento; la intransitividad sería lo contrario). Pero este criterio no siempre se cumple, ya que hay construcciones que manifiestan paso o tránsito y no por ello se califican de transitivas, como sucede con las atributivas y de estado, las de identificación y existencia (vgr. María parece lista; Xosé é avogado [José es abogado]; o can está enfermo [el perro está enfermo]; no monte abundan os toxos [en el monte abundan los tojos]); y existen otras construcciones que pudiendo ser transitivas no evidencian esa idea de tránsito hacia otra entidad, como son las reflexivas, en las que la acción permanece en el sujeto (vgr. María lávase e Xoán peitéase [María se lava y Juan se peina]). Por otra parte, las definiciones por las que la transitividad es la propiedad semántica de aquellos verbos que expresan una acción que transita de un agente hasta un paciente o término, no justifican por qué existen construcciones transitivas e intransitivas con verbos que no designan acción, ni construcciones que requieren complementación sin implicar la actuación de un agente sobre un paciente, ni por último construcciones con el papel de paciente o afectado sobre las que no actúa un agente (vgr. enfermar, padecer).

Frente a todo lo anterior, algunas corrientes de la lingüística actual como el funcionalismo de Dik (1997) y la gramática sistémica de Halliday (1994) prestan especial atención a las dimensiones sintáctica, semántica y pragmática o informativa así como a su interrelación, esto último es lo que nosotros defendemos. Particularmente hay tendencias de la gramática léxica funcional (DALRYMPLE, 1999) que vinculan sintaxis y semántica al subrayar la necesaria correspondencia entre los papeles temáticos desempeñados por los argumentos y las funciones gramaticales. En general sostienen además que los fenómenos de transitividad e intransitividad se han de aplicar a la cláusula en su totalidad y no sólo al verbo.

El generativismo de autores como Hernaz \& Brucart (1987) así como el funcionalismo de Blinkenberg (proyectado en CANO AGUILAR, 1987) y Vilela (1999) valoran y toman como base la construcción al establecer una vinculación sintáctico-semántica entre verbo y complementación cuando señalan que el término transitivo implica una vertiente semántica, que viene dada por el carácter incompleto del verbo, y otra sintáctica, que es la cohesión estructural entre los elementos de la oración; por eso la transitividad abarca 
no sólo las estructuras de complemento directo sino también las de compl. indirecto, circunstancial y compl. prepositivo. Este punto de vista supone una consideración restringida de la intransitividad y se desvía de los presupuestos que estamos defendiendo en este trabajo.

La gramática relacional de Perlmutter (1980) y Comrie (1989) defiende que las estructuras intransitivas derivan sintácticamente de las transitivas básicas a partir de la promoción del complemento directo a sujeto, lo que significa que existe una función sujeto superficial que se corresponde con un complemento directo de la estructura profunda (vgr. Pepe abanea a pereira / a pereira abanea [Pepe sacude el peral / el peral se mueve]).

La gramática de la construcción y la gramática cognitiva, en las que podemos destacar a Langacker (1991, p. 275-306), Kay (1997), Goldberg (1995; 2003, p. 219-223), se centran en la construcción y pretenden asociar el plano sintáctico con el semántico, no separar la lengua de las restantes habilidades cognitivas y tener en cuenta la relación entre el léxico y la gramática así como la relación entre la experiencia humana y la gramática, algo que nos parece lo más adecuado para el estudio de las estructuras intransitivas y transitivas.

Las gramáticas de lenguas minorizadas como las del gallego o la del catalán de Badia i Margarit permiten también extraer algunos datos sobre esta cuestión. La gramática de Badía (1995, p. 247-302) aplica la transitividad a estructuras que precisan complemento directo para completar su sentido, por consiguiente parece deducirse que las construcciones sin compl. directo entrarían en la dimensión de la intransitividad. Además de esto, frente a otros investigadores como Vilela $\left(1999^{2}\right.$, p. 71$)$ o Freixeiro (2000, p. 649) que consideran transitivas las estructuras con verbos de movimiento seguidos de un complemento (vgr. vai á escola [va a la escuela]), Badía parece situar este tipo de construcciones en la dimensión de la intransitividad.

Por lo que respecta a las gramáticas de Álvarez, Regueira \& Monteagudo (1986), Costa et al. (1989), Freixeiro (2000), Álvarez \& Xove (2002) se sirven de criterios de corte tradicional en unos casos y funcional o ecléctico en otros. Las gramáticas de Costa et al. y Freixeiro presentan una concepción bastante restringida de la intransitividad, y la aplican en exclusiva a las estructuras monoclausales, de este modo no serán calificadas de intransitivas las estructuras con un predicado seguido de compl. indirecto, compl. circunstancial y compl. prepositivo. Por contra, las gramáticas de Álvarez et al. manejan una concepción más amplia de la noción y la aplican no sólo a estructuras monoclausales sino también a aquellas con un predicado seguido de complemento indirecto, circunstancial y prepositivo.

Nosotros, desde una perspectiva amplia, de carácter transversal, consideramos construcciones intransitivas las ceroargumentales, las monoargumentales inergativas, cuyo sujeto tiene propiedades características de tal función (vgr. María sorrí), las monoargumentales inacusativas cuyo único argumento tiene propiedades de compl. directo y sujeto (vgr. a roupa 
seca [o sol seca a roupa]), las biargumentales de complemento indirecto y circunstancial, las de complemento prepositivo, las construcciones con verbos pronominales (exepto las reflexivas y aquellas en las que el clítico es marca de compl. directo), las atributivas (con atributo y predicativo del sujeto) y en general las de voz pasiva. Estas estructuras, frente a las transitivas que presentan el esquema sintáctico prototípico sujeto-predicadocompl. directo y un esquema semántico agente-acción-afectado, muestran esquemas semánticos y sintácticos con diferentes funciones y papeles semánticos, nuevos valores aspectuales (buena parte de las intransitivas son atélicas), en la mayoría de los casos no permiten la sustitución pronominal por clítico acusativo ni dejan ningún resto pronominal en la conversión temática y admiten en general con más facilidad los cambios de orden de sus argumentos sin que se introduzcan nuevos elementos (vgr. o escándalo chegou con ela / con ela chegou o escándalo [con ella llegó el escándalo]; María comeu o pastel / o pastel comeuno María [el pastel lo comió María]). Además de esto, la cohesión semántico-sintáctica y rítmica entre predicado y complemento no directo tiende a ser menos estrecha que la que se produce entre predicado y complemento directo.

En nuestra opinión, el fenómeno de la intransitividad hay que abordarlo desde la dimensión de la construcción (cfr. GOLBERG, 1995; 2003; CROFT, 1991; HALE; KEYSER, 2002; BORER, 2004), situar la interrelación de los elementos de la estructura clausal como eje del análisis gramatical y hacer derivar de la construcción, más que del verbo, las funciones semánticas, sintácticas y pragmáticas.

La consideración de la intransitividad no debe partir de la delimitación de un subtipo de verbo sino de la actualización de un predicado en una determinada construcción o estructura clausal y ha de tener en cuenta las dimensiones sintáctica y semántica (ámbito clausal sintáctico-semántico), así como pragmática (ámbito extraclausal) cuando estas nos pudedan aportar datos esclarecedores en relación en el hecho analizado. De este modo, frente a los modelos más formales -el de Chomsky y la escuela de Massachusetts (cfr. CHOMSKY, 1999, p. 87 ss.; LASNIK, 2000) y los matemáticos de la corriente LFG (BRESNAN, 2000) - que, logrando excelentes resultados, reconocen y enfatizan la existencia de un marco sintáctico propiamente dicho y abordan el estudio de los fenómenos sintácticos desde un punto de vista autónomo, el enfoque que seguimos para estudiar la intransitividad es el que se basa en el modelo interdisciplinar que tiene en cuenta los diversos componentes que interactúan, sintaxis, semántica (LEVIN; RAPPAPORT, 1995; FABER; MAIRAL, 1999), léxico y en ocasiones también aquellos fenómenos integrados en el campo de la estilística y la pragmática (LEECH, 1998; ESCANDELL, 1999), esto es, los factores de tipo contextual y situacional que incluyen al emisor, destinatario, enunciado, y la intención, contorno o contexto extraverbal, etc., y que condicionan en muchos casos el orden de palabras y el significado. Por un camino semejante iban hace algunos años las afirmaciones de Hopper \& Thomson (1980, p. 251), "Transitivity involves 
a number of components [...] These components are all concerned with the efectiveness with which an action takes place, e.g. the punctuality and telicity of the verb, the conscious activity of the agent, and the referentiality and degree of affectedness of the object".

Así pues, conviene reafirmar que resulta más preciso hablar de construcciones intransitivas que de verbos intransitivos o verbos transitivos usados intransitivamente, aunque por razones de carácter práctico y por la fuerza de la costumbre a veces se siga utilizando esta denominación, conscientes de su imprecisión.

\section{La Semántica De Los Eventos}

Desde un punto de vista genérico, decimos que las construcciones transmiten procesos, acciones, evento ${ }^{2}$ y estados. Los distintos autores usan conceptos y términos parecidos, así se habla de estados, actividades, logros y realizacións (VENDLER 1967, p. 122); eventos y estados (HUB FARIA et al. 1996, p. 364); acciones, estados, procesos (LÓPEZ, 1996, p. 169; MORENO CABRERA, 1997, 2003ㄹ ; VILELA, 1999, p. 350); acciones, transiciones, procesos (PUSTEJOVSKY, 1998); acciones, procesos, posiciones, estados (ÁLVAREZ; XOVE, 2002).

Los procesos representan el tránsito de un estado a otro, protagonizado por un individuo o entidad, que son experimentantes (SOTO ANDIÓN, 2005). Los procesos pueden ser de diversas clases según el cambio experimentado por el sujeto en relación con una determinada propiedad o cualidad. En ocasiones una misma estructura implica al mismo tiempo dos procesos paralelos o superpuestos, de este modo "enflaquecer" tanto puede mostrar un valor diminutivo como también empeorativo; "ablandar" traduce un proceso diminutivo en la medida en que una entidad disminuye su dureza y modificativo por cambiar o modificar esa misma entidad su estado inicial. Aquí discriminamos los siguientes tipos de procesos:

i. Adquisitivo o aumentativo y privativo o diminutivo: el primer par se encuentra en una entidad que adquiere una propiedad que no tenía o que la aumenta en volumen o extensión (vgr. engordar, anchear). El segundo par lo encontramos cuando una entidad o pierde y diminuye una propiedad o reduce su volumen y extensión (vgr. enflaquecer, menguar, consumirse).

ii. Intensificativo y atenuativo: acontece cuando una entidad aumenta o disminuye el grado y la intensidad de una determinada propiedad o cualidad (vgr. acentuarse, agravarse, ablandar).

\footnotetext{
${ }^{2}$ Evento es un concepto que utilizamos con un doble significado. Por una parte puede señalar un determinado papel semántico del sujeto (vgr. estalló la guerra, acción-evento), por otra también alude al verbo o a la construcción y se concreta fundamentalmente en acciones, eventos, procesos y estados.

${ }^{3}$ En esta obra publicada en 2003, el autor llama "tipos de suceso" a los estados, procesos y acciones.
} 
iii. Transformativo y modificativo: cuando una entidad experimenta una transformación de su estado (vgr. evaporarse, callar, converterse, cambiar) o una modificación del mismo (vgr. clarear algo o cabelo, asentarse un viño).

iv. Mejorativo y empeorativo: una entidad experimenta una mejora o empeoramiento de su estado (vgr. progresar, aliviar, subir; empeorar, infectarse).

v. Adaptativo: supone que una entidad se adapta a una nueva situación o medio (vgr. adaptarse, habituarse, acostumarse).

vi. Continuativo: es aquel proceso que, a diferencia de los anteriores, no manifiesta cambio ni alteración en la entidad o individuo en los que se desarrolla (vgr. durar, continuar...).

Las acciones indican actividad y dinamismo, de tipo físico o mental, de un individuo o de una entidad (los que la tradición denomina agentes y fuerzas). Podemos decir que "activities, like states, are atelic, but unlike states, they are dynamic" (ROTHSTEIN, 2004, p. 17).

Los eventos son los distintos hechos que traducen sobre todo procesos o acciones. En ocasiones, los eventos aparecen al lado de los estados como tipos de acontecimiento. Algunos autores (CROFT, 1991; MORENO CABRERA, 1997; VAN HOUT, 2002...) se sirven de esta denominación para, desde una perspectiva amplia, abordarlos como categorías semánticas y conceptuales que determinan esquemas y tipos eventivos en función de los participantes y establecen relaciones eventivas de acuerdo con los valores temporales. Concretado en el sujeto, el papel semántico evento puede mostrar interferencias y puntos de contacto con el papel de afectado; el propio contenido de ambos derivado de cada construcción particular será lo que mejor los distinga, de este modo el sujeto de estalou a guerra funcionará más como evento que como afectado.

El estado es un papel semántico que por lo general se aplica a condiciones que carecen de un desarrollo temporal interno; podemos hablar de su duración, pero no de su progreso o culminación. Como dice Rothstein $(2004,14)$ : "states or stative eventualities are cumulative and non-dynamic, i.e. [-telic, -stages]. They are also totally homogeneous". Los estados designan la condición de una entidad o individuo, situaciones de tipo locativo cuyo papel semántico es el de situado (vgr. está en Vigo; o camiño sae de Roncesvalles), caracterizaciones " características o propiedades (vgr. está moi guapa) " atribuídas a dichas entidades o individuos cuyo papel semántico es el de portador de estado y caracterizado. También se pueden considerar estados las construcciones de posesión (vgr. a casa perténcelle a seu pai; a carteira é dela), de dimensión espacial o temporal (vgr. o camiño prolóngase ata Samil) y las de existencia (vgr. existir). Por último, cabe añadir que los estados pueden tener carácter permanente o temporal y ser consecuencia de un proceso o acción previos: quedar, parar, calmarse... suelen formar construcciones en las que el estado es consecuencia de una actividad anterior. 


\section{CONSTRUCCIONES InTRANSITIVAS PROTOTÍPICAS CON QUEDAR}

Tomando como base los anteriores presupuestos, en las siguientes páginas daremos cuenta de distintos esquemas semántico-sintácticos nucleados por quedar, en los que este verbo es núcleo de predicado y, de acuerdo con el tipo de esquema en que funcione, adquiere valores tanto de estado en sentido amplio como dinámicos. Existen en la lengua gallega más estructuras de las que han sido seleccionadas, pero con las prototípicas descritas aquí es posible llegar a conocer el comportamiento de estas construcciones. Además, con el fin de presentar una visión más amplia de los datos ofrecidos, contrastaremos los análisis de las muestras de nuestro corpus con los principales resultados que ofrecen otras lenguas romances próximas.

Para realizar la parte empírica de este trabajo nos ayudamos de los parámetros (cfr. SOTO ANDIÓN, 2006) que a continuación señalamos de forma gráfica y esquemática:

\section{VERBO Quedar}

«Significado» de acuerdo con la estructura en la que funciona

EJEMPLOS (lengua escrita con indicación de obra, número de revista o periódico y página. Lengua oral con indicación del lugar y edad del informante)

ESQUEMA sintáctico y semántico ${ }^{4}$

SUJETO (rasgos semántico-sintácticos más relevantes)

COMPLEMENTACIÓN ${ }^{5}$ (rasgos semántico-sintácticos más relevantes)

${ }^{4}$ Llamamos esquema sintáctico al molde sintáctico o esquema de funciones sintácticas desempeñadas por los argumentos o participantes de la construcción (Vid. también LAZARD, 1998, p. 11146). Son esquemas semánticos los diversos moldes que agrupan los papeles semánticos ejercidos por dichos argumentos. Nuestra posición a este respecto es maximalista, lo que significa que manejamos un variado y completo conjunto de esquemas y papeles semánticos, que dan cuenta con mayor exactitud de los múltiples eventos transmitidos; es una postura que difiere de aquellas que se sirven de un número de esquemas y papeles semánticos excesivamente reducido. Dik (1997, p. 122) comenta, en relación con las funciones semánticas que propone en su obra, que no se trata necesariamente de una lista cerrada y no está seguro de que resulten suficientes para recoger la diversidad de contenidos que se transmiten por ejemplo a través de las preposiciones. Autores como Van Valin \& Lapolla (1997) y Kibrik (1997, p. 279-346) agrupan bajo la etiqueta de macrorroles e hyperroles (actor and undergoer) los papeles semánticos que manifiestan distintas relaciones semánticas con rasgos comunes.

${ }^{5}$ La complementación se refiere a las distintas funciones sintácticas de la construcción que precisan otras funciones básicas como son el sujeto y el predicado. 
CONSTRUCCIÓN: voz (activa, media o pasiva) ${ }^{6}$; valor pronominal y uso de se; valores aspectuales ${ }^{7}$

OTRAS LENGUAS PRÓXIMAS

El método empleado para describir este tipo de estructuras opera relacionando semántica, sintaxis y léxico. Langacker (1991) defiende que no se puede disociar el léxico de la gramática, del mismo modo que no se puede separar la estructura sintáctica de la semántica. Lyons (1993, p. 135 ss.) considera que el significado oracional es resultado del significado léxico y gramatical, es dicir, del significado de los lexemas constituyentes y de las construcciones gramaticales que relacionan sintagmáticamente esos lexemas. Gutiérrez Ordoñez $(1996$, p. 42, 1997) considera la existencia de una valencia sintáctica, semántica y formal aplicable a los signos, que sirve para delimitar su combinatoria. Dik (1997) utiliza las funciones gramaticales en tres niveles diferentes (funciones semánticas, pragmáticas y sintácticas) y sostiene que la sintaxis no es autónoma, que hay dependencia entre el componente sintáctico y el semántico, sin que esto impida la existencia de principios internos a la propia sintaxis. Croft (2001, p. 128) establece una interconexión entre lo que denomina la estructura conceptual basada en las experiencias del hablante y la estructura sintáctica y semántica. En esta línea parece estar también Moreno Cabrera (2003).

${ }^{6}$ Manejamos los tres tipos básicos de voz: activa, media y pasiva. La pasiva en gallego, francés y otras lenguas (DIMITROVA-VULCHANOVA, 1999; ARAUJO, 2001, p. 19-30) vuelve intransitiva la construcción mediante la presencia de se en la pasiva sintética, o mediante la reorganización de los participantes en la pasiva analítica, para Martinet (1987, p. 308) "pasiva expandida", situando antes del verbo la entidad afectada y quedando el agente o en posición posverbal o en la indeterminación. En gallego y en otras lenguas la pasiva analítica pierde terreno en favor de la construcción con $s e$. La voz media está formada por estructuras formalmente activas y por estructuras pronominales con se (esto puede ampliarse en SÁNCHEZ LÓPEZ, 2002), presenta un sujeto afectado, que puede ser [+animado], sin consideración de un agente que realice el evento, aunque puede existir un causante. Halliday \& Mathiessen (2004, p. 280-305) aproximan la voz media a un tipo de cláusulas que actúa preferentemente bajo el patrón del denominado modelo ergativo y cuyo sujeto se caracteriza por tener un papel semántico de Medium.

${ }^{7}$ Bajo la denominación de valores aspectuales o aspectualidad (MIGUEL, 1999, p. 2977 3060; BERTINETTO; D. DELFITTO, 2000, p. 189-226; THIEROFF,. 2000, p. 265-305) incluimos tanto el aspecto léxico o aktionsart -modo del evento - derivado del lexema verbal en función de predicado, como el aspecto gramatical derivado de procedimientos morfológicos y sintácticos: sujeto y complementos, presencia de $s e$, perífrasis, adverbios y locuciones adverbiales, tiempos verbales, afijos derivativos y flexivos, negación (para esto último vid. también ZANUTTINI, 1997). Dentro de estos valores y siguiendo a los autores antes mencionados discriminamos los siguientes contenidos: -Estativo/dinámico, el primero se da de forma homogénea a lo largo del tiempo sin mostrar cambio ni proceso, el segundo implica una actividad -física o psicológica - o un cambio que se manifiesta en unos resultados y admite fases (inceptiva, media, terminativa o cesativa); -Puntual o instantáneo: acontece en un momento (vgr. estourar) frente a durativo o progresivo: progresa a lo largo del tiempo (vgr. quecer); -Atélico/télico: un evento resulta atélico cuando se mantiene y dura un tiempo no determinado; normalmente admite la complementación con durante; un evento es télico cuando no muestra permanencia (vgr. chegar) ni manifiesta duración; -Simple y semelfactivo: consta de una fase (vgr. dar un bico) frente a iterativo, múltiple, intermitente que consta de varias fases (vgr. golpear, metrallar, guiñar); -Habitual: se repite con determinada frecuencia (vgr. ler); Permanente: se repite de manera constante (vgr. a terra xira); -No intensivo (vgr. chover) frente a intensivo (vgr. arroia, chove máis) y atenuativo (vgr. barruza, chove miúdo). 
Desde estas bases teóricas, analizaremos algunas construcciones intransitivas prototípicas con quedar, que nos permitan extraer algunas conclusiones acerca de su comportamiento.

\subsection{Mantenerse, Estar En Un Lugar, Dirección O Situación}

1. abriu o xornal que ali quedara e encontrou medio roída a páxina (ESC, 26)

2. aquela noite quedaba en Vigo a durmir (OCT, 12)

3. Sáinz queda a 500 metros do seu terceiro título por arderlle o motor do seu Toyota no Rallye de Gran Bretaña (OCG, 2511-98, 34)

4. foi unha das profesoras da pasantía comigo e dixome: iui mira que desde logo queda lonxe, eh! (PONTEDEUME-A Coruña, 41)

5. fun dous anos á escuela a Xestoso, e despois fun pa Silleda, quedábame máis cerca (ACIVEIRO- FORCAREI-Pontevedra, 31)

El esquema sintáctico es sujeto-predicado, sujeto-predicadocircunstancial y el respectivo esquema semántico situado-situación, situado-situación-locación espacial.

El sujeto puede posponerse al predicado sobre todo cuando el emisor establece el centro de atención informativa en el complemento o en la situación que refleja el predicado; la no animación y la presencia de dativo favorecen asimismo la posposición ${ }^{9}$. Sus rasgos semánticos son [ \pm animado], en general [+concreto], [+común], [-control], o [+control] con entidades animadas que manifiestan voluntad e intencionalidad en relación con los hechos expresados.

El complemento no resulta obligatorio en aquellas construcciones en las que el verbo adquiere significado pleno (vgr. nós marchamos agora, pero María queda [aquí, na casa...]). En las restantes, funciona un circunstancial desempeñado fundamentalmente por una frase adverbial o preposicional con el papel semántico sobre todo de locación espacial, aproximacion (vgr. iso queda por/contra Silleda), distancia y cuantificación, condición (vgr. coa túa axuda non quedaría a esa distancia), concesión (vgr.

\footnotetext{
${ }^{8}$ El papel semántico situado señala la entidad animada o inanimada que está posicionada en un punto determinado del espacio. Se diferencia así del papel semántico portador de estado, que indica el estado específico de una entidad o individuo representados en el sujeto.

${ }^{9}$ La posposición del sujeto al predicado está determinada en general por la tematización, los valores aspectuales, la modalidad clausal, la animación, el control, la voz, el carácter semántico del verbo y de la construcción (cfr. BALTIN, 2001, p. 226-254). También la definitud juega un importante papel; el efecto de definitud (Definiteness Effect, cfr. BELLETTI, 1987, p. 173) en la posición del sujeto se comprueba claramente en las construcciones existenciales (vgr. hai un home na habitación / "hai o home na habitación / "un home hai na habitación) y con otros verbos (vgr. apareceron sinais de violencia no seu corpo / han aparecido señales de violencia en su cuerpo / "sinais de violencia apareceron no seu corpo /"señales de violencia han aparecido en su cuerpo).
} 
mesmo coa túa axuda quedaría lonxe del). En paralelo aparece a veces un dativo y/o compl. indirecto con el papel semántico de beneficiado o perjudicado por un estado de cosas dado, y un predicativo que señala un estado del sujeto (vgr. esa noite quedei canso en Vigo).

La construcción es de voz activa o de situación. Admite se cuando el sujeto es animado para indicar su carácter indeterminado. También se registra en forma pronominal, con un clítico variable en número y persona (vgr. quedeime na casa) que refuerza el papel de afectado del sujeto y centra en él la situación expresada. En las estructuras con sujeto inanimado se documentan a menudo tiempos de presente (vgr. Vigo queda para o sur). Los valores aspectuales prototípicos son estativo y atélico.

Otras lenguas próximas como el español presentan construcciones de estas características (vgr. queda lejos; me queda más cerca de tu casa). El valor aproximativo espacial se construye con la preposición hacia (vgr. la vivienda queda hacia el norte). En muchos casos y a diferencia del gallego tiene carácter pronominal (vgr. quedarse en casa a dormir; Sáinz se queda a 500 metros de su título; la conversación quedó/se quedó allí). El portugués se vale de la solución ficar, no pronominal y seguida de circunstancial en la complementación (vgr. este fim de semana vou ficar em casa; ficou comigo; muitos insetos aínda ficaram en meio ás folhas; ficou-lhe uma cicatriz no rosto), a veces en alternancia con el verbo ser (vgr. minha casa fica/é perto da igreja). El italiano usa predicados como rimanere, restare (vgr. restare a casa; il bare remane vicino) $u$ otros (vgr. la conversazione finì lì [a conversa quedou alí]) y el valor aproximativo se construye con verso, dalla parti di.

\subsection{Mantenerse En Un Cierto Estado o Pasar A Él Como Consecuencia de Algo}

6. sen atrevérense a iniciar a toma da casa por medo a que quedase algún deles vivo (DEUS, 16)

7. un mozo berra, racha a camisa negra, queda co peito espido (OCT, 365)

8. $\quad$ con trinta meses quedou orfo de nai (OCG04-02-99, 3)

9. a miña compañeira abriu un queixón e quedouse toda asombrada porque ela pensaba que me traía a chave (O PEREIRO-Ourense, 18)

El esquema sintáctico es sujeto-predicado-predicativo y el esquema semántico portador de estado ${ }^{10}$-estado-modo.

El sujeto acostumbra a preceder al predicado y tiene los rasgos semánticos [+animado], en general [+concreto], [+común], [-control], o [+control] con sujetos animados que manifiestan voluntad e intencionalidad en relación con los hechos expuestos.

${ }^{10}$ Papel semántico característico de aquellos sujetos que funcionan en esquemas de estado. Señala entidades o individuos que presentan algún tipo de estado o condición. 
El complemento resulta obligatorio. Está representado por una frase preposicional y por una frase adjetiva variable en género y número, que muestran un determinado modo de estar de la entidad o individuo en función de sujeto. De forma opcional puede acompañar algún circunstancial con el papel semántico sobre todo de locación temporal y espacial, causa (vgr. onte quedou canso con ese traballo), condición (vgr. coa túa axuda non quedaría canso), concesión (vgr. mesmo coa túa axuda quedaría canso)...

La construcción es de estado, admite se con sujeto animado para indicar su carácter indeterminado. También se registra una variante pronominal, con un clítico variable en número y persona, más usual en unas estructuras (vgr. quedeime espido) que en otras que parecen interferencia del español (vgr. quedeime de pedra??). La presencia de clítico refuerza el papel de afectado del sujeto, centrando en él el estado expresado. Los valores aspectuales prototípicos son estativo y atélico.

En otras lenguas como el español se documentan construcciones de este tipo (vgr. tuvieron miedo a que quedase alguno vivo), a veces de tipo pronominal (vgr. se quedó desnudó). En portugués la estructura es no pronominal y suele funcionar con complemento de causa (vgr. ele ficou mudo por causa de um acidente; ficou naquela situaçao por três dias; ficou alegre). El italiano emplea las formas restare o rimanere (vgr. quedou satisfeito dos resultados; restò soddisfatto dei risultati; rimanere di stucco).

\subsection{Dejarse U Olvidarse Algo En Alguna Parte}

10. a ver o carné, señora; quedoume no río, e dixo non sei cómo se arreglan ostedes... (LALÍN-Pontevedra, 70)

El esquema sintáctico es sujeto-predicado-circunstancial y el esquema semántico afectado-acción-locación espacial.

El sujeto puede posponerse al predicado principalmente cuando el centro de atención informativa establecido por el emisor está en la propia acción o en el complemento. Sus rasgos semánticos son [-animado], [+ concreto], en general [+común], [-control].

El complemento resulta obligatorio. Está representado por una frase preposicional o adverbial, que señala el lugar en donde algo fue olvidado. En muchas estructuras acompaña un dativo y/o compl. indirecto, refiriendo la persona afectada por la acción descrita. De forma opcional puede funcionar algún circunstancial con el papel semántico sobre todo de locación temporal, causa (vgr. coa présa quedoume o carné onte na casa), condición (vgr. co teu aviso non me quedaría o carné na casa)...

La construcción se aproxima a las de voz media, con un sujeto no agentivo. No admite se y se usa en P3 singular o plural. Los valores aspectuales son dinámico, télico.

Otras lenguas tienen esta construcción. El español utiliza predicados 
como dejar/-se, olvidar/-se (vgr. ha dejado/olvidado la cartera en el río). El portugués usa generalmente esquecer/-se y el italiano se vale de la estructura dimenticarsi di.

\subsection{Determinar Un Encuentro, A Veces Señalando Lugar y/u HORA}

11. un dia quedaban para comer nunha churrasquería (ESC, 92)

12. o viernes quedaremos na miña casa (RIBEIRA-A Coruña, 28)

13. quedei con Rafa mañán ás dez (LOUREIRO-COTOBADE-Pontevedra, 80)

El esquema sintáctico es sujeto-predicado, sujeto-predicado-compl. prepositivo $^{11}$, con el respectivo esquema semántico agente-acción, agenteacción-término ${ }^{12}$.

El sujeto se antepone al predicado en el orden no marcado. La posposición es frecuente cuando el emisor centra la atención en el lugar o en la hora (vgr. hoxe ás catro quedei con Elsa). Sus rasgos semánticos son [+humano], [+concreto], [+común], [+control].

El complemento no resulta obligatorio cuando el sujeto es plural o compuesto (vgr. quedamos Pepe e mais eu). En las demás construcciones funciona un compl. prepositivo, de referente humano, representado por una frase preposicional de estructura $(\mathrm{con}+\mathrm{fn})$ que indica la persona con la que alguien se va a encontrar. A menudo funciona un circunstancial, en posición preverbal o posverbal, que expresa un punto en el espacio y/o en el tiempo para encontrarse dos o más individuos; también es frecuente un circunstancial de estructura (para+cláusula), con el papel semántico de fin (vgr. quedei con ela ás tres para comer).

La construcción es activa. Puede estar en singular o plural. En plural su significado puede ser doble, esto es, referirnos a dos o más individuos que se citan entre sí, o aludir a dos o más individuos que se ven con otra persona (vgr. quedamos con María ás nove). Es posible el uso de $s e$ para indicar sujeto indeterminado. En otros contextos la presencia de clítico

\footnotetext{
${ }^{11}$ La función sintáctica complemento prepositivo, también llamado complemento preposicional y objeto preposicional por aquellos autores partidarios de la transitividad preposicional (HAPP, 1978; ALARCOS, 1994) señala la función constituida formalmente por una frase preposicional introducida por las preposiciones $a$, con, de, en, por, sobre... En algunas construcciones aparece sólo una de ellas, lo que significa que el cambio de preposición implica una alteración semántica, en otras es posible la alternancia expresando significados muy próximos (vgr. falar de/sobre/acerca de; discrepar de/sobre/acerca de).

${ }^{12}$ Llamamos término al papel semántico que señala la entidad animada o inanimada en la que desemboca, se proyecta o converge cualquier tipo de evento, incluido el derivado de esquemas de relación (vgr. tratar con alguén). Es característico de la función complemento prepositivo y formalmente está representado por una frase preposicional de estructura (a, con, de, sobre, a cerca de...+ frase nominal).
} 
da lugar a un valor pronominal y a un diferente significado (vgr. quedouse comigo [burlarse]). Los valores aspectuales prototípicos son dinámico, télico, a veces iterativo.

Otras lenguas como el español se sirven de esta construcción (vgr. quedé con ella a las cinco). En portugués adquiere el significado de mantener cierta relación amorosa con alguien (vgr. ele e ela ficaram ontem à noite). El italiano cambia la estructura y opta por la forma dare appuntamento (vgr. ha dato appuntamento a Marina alle due).

\subsection{Estar Algo De Un Determinado Modo, Sentar, Caer}

14. na xente gorda hai que tratar de fase-la roupa a medida, non é chejares ali, poñeres unha chaqueta, ala, estame ben de manga e que che queda de delantera pequena (RIBEIRA-A Coruña, 55)

El esquema sintáctico es sujeto-predicado-predicativo y el esquema semántico portador de estado-estado-modo.

El sujeto puede posponerse al predicado cuando el emisor centra el interés en el evento o en el complemento, cuando funciona un dativo y cuando el sujeto resulta no definido y no animado. Sus rasgos semánticos son [-animado], [+concreto], [+común], [-control].

El complemento es obligatorio. Está representado de ordinario por una frase adjetiva o por una cláusula (vgr. quédache que nin pintada), que señalan un determinado modo de estar, caer, sentar la entidad en función de sujeto. Con frecuencia acompaña también algún dativo y/o complemento indirecto refiriendo la entidad afectada.

La construcción es de estado, se usa en P3 singular o plural y no admite $s e$. Los valores aspectuales prototípicos son estativo, atélico, a veces intensivo.

Otras lenguas como el español utilizan esta estructura con predicados como quedar, sentar (vgr. el traje le queda/sienta bien). El portugués adopta ficar, cair (vgr. o terno fica horrível nele, não lhe cai bem; fica-lhe bem o verde) y en italiano se documenta regularmente stare (vgr. questa pettinatura ti sta molto bene).

\subsection{Comprometerse Con Otra Persona Para Hacer Algo}

15. entonces ese día á noite quedamos en que as outras compañeiras nos viñeran chamar a nós (O PEREIRO-Ourense, 18)

16. quedou de vir e non apareceu (LOUREIRO-COTOBADEPontevedra, 80)

El esquema sintáctico es sujeto-predicado-compl. prepositivo y el esquema semántico agente-acción-término. 
El sujeto suele preceder al predicado y se caracteriza por los rasgos semánticos [+humano], [+concreto], [+común], [+control].

El complemento resulta obligatorio. Está desempeñado por una frase preposicional sin determinante, de estructura (de+cláusula de infinitivo), (en+cláusula con que/cláusula de infinitivo), que indican el evento que constituye el compromiso asumido por uno o varios individuos. La estructura con en refleja mayor firmeza, seguridad y probabilidad para que el compromiso se cumpla. Resulta menos frecuente su funcionamiento en una cláusula simple y con infinitivo (vgr. María quedou en vir, así que axiña ha chegar). Frente a esto, la estructura con de refleja más inseguridad, menos probabilidad de que el compromiso logre su fin. Con carácter opcional, pueden acompañar algunos circunstanciales con el papel semántico sobre todo de loc. temporal, fin (vgr. quedou de vir ás oito para saírmos).

La construcción es activa y por lo regular con valor prospectivo. Admite se indicando sujeto indeterminado (vgr. se se queda de ir vaise). Los valores aspectuales prototípicos son dinámico " el sujeto expresa una actividad en forma de compromiso adquirido “, y télico.

Otras lenguas como el español acostumbran a utilizar la estructura (en + cláusula) (vgr. quedamos en vernos al día siguiente). En portugués se registra (de+cláusula) y predicados como ficar, combinar (vgr. ela ficou de vir sem falta; amanhap combinamos de nos encontrar na saída). El italiano selecciona otros predicados y la estructura (de+cláusula) (vgr. concordammo di vederci il giorno dopo).

\subsection{Tener Un Evento El Desenlace O Resultado Que Se Indica}

17. tuveron así unha serta rivalidá, pero chekhaba o momento da verdá e ikhual quedaba en nada se dabas con xente comprensiva (O GROVE-Pontevedra, 60)

El esquema sintáctico es sujeto-predicado-compl. prepositivo y el esquema semántico evento ${ }^{13}$-acción-término.

El sujeto puede preceder o seguir al predicado. La posposición la favorece el semantismo de la construcción y la no animación del sujeto. Sus rasgos semánticos son [-animado], [+concreto], en general [+común], [-control]. Resulta frecuente con nombres genéricos como trato, acuerdo, proyecto, asunto, cosa...

El complemento es obligatorio. Está representado sobre todo por una frase preposicional de estructura $(e n+f n)$ y (en + cláusula) (vgr. o trato quedou en axudarmos alí todos), con un referente que puede ser un evento o una entidad con los rasgos [-animado] y [ + concreto], que indica el punto en el que remata una acción previa. De manera opcional, puede funcionar

${ }^{13}$ Evento es un papel semántico referido tanto al sujeto como al verbo predicado o a la construcción. En este ejemplo refiere en el sujeto cualquier suceso, acontecimiento o caso. 
algún circunstancial con el papel semántico de loc. espacial y temporal, causa.

La construcción es activa, se usa en P3 singular o plural y no admite se. Resulta frecuente en la modalidad interrogativa (vgr. en que quedou a cousa?) y en contextos negativos (vgr. a cousa non quedou en nada). Los valores aspectuales prototípicos son dinámico, télico, terminativo.

Otras lenguas próximas como el español presentan construcciones similares (vgr. no quedaron en nada). En portugués se conoce esta estructura con en o con adjetivo (vgr. saímos duas vezes e ficou nisso; o jogo terminou empatado [o xogo rematou en empate]), lo mismo que en italiano (vgr. finire in niente).

\subsection{HABER UnA Cosa, Sobrar}

18. dos poderes de antano quedara unha sotana (ESC, 11)

19. comeramos as papas e non nos acordara que quedaran dous platos delas (MARÍN-Pontevedra, 60)

El esquema sintáctico es sujeto-predicado y el esquema semántico portador de existencia/presencia ${ }^{14}$-existencia/presencia.

El sujeto se pospone con frecuencia al predicado debido al semantismo de la construcción así como a la no animación y no agentividad. Sus rasgos semánticos son [-animado], [+concreto], en general [+común], [-control].

El complemento no resulta obligatorio. En ocasiones funciona algún circunstancial, sobre todo con la estructura (para+frase nominal/ cláusula), con el papel semántico de fin, dirección y destino, locación temporal, causa (vgr. con tan pouca xente quedou comida para mañá). Además puede acompañar un dativo y/o compl. indirecto, de referente animado, con el papel semántico de afectado.

La construcción es de estado y no admite se. La persona es la tercera singular o plural y los valores aspectuales prototípicos son estativo, atélico.

Otras lenguas como el español presentan construcciones de estas características, por lo general con sujeto pospuesto (vgr. aún quedan algunas manzanas), también el italiano (vgr. resta ancora qualche mela), mientras que el portugués opta por los predicados ficar, sobrar, ter, restar (vgr. só sobrou/tem/resta um pouquinho de açúcar; o que nos ficou daquele dinheiro foi bem pouco).

${ }^{14}$ Papel semántico característico de aquellos sujetos que funcionan en esquemas de existencia/ presencia. Señala entidades o individuos que presentan algún tipo de existencia o presencia y la inversa inexistencia o ausencia. 


\subsection{FALTAR Algo, Restar}

20. por recobrar un minuto a vista dos ollos eu daba de boa gana canto me queda de vida (OCT, 207)

21. perdóalle ó teu rei, que tanta gana ten agora de falar cun amigo, exa lle queda pouco tempo (MDR, 144)

22. queda un día para o meu cumpreanos (SANTIAGO-A Coruña, 35)

El esquema sintáctico es sujeto-predicado y predicadocircunstancial, con el respectivo esquema semántico portador de existencial presencia-existencia/presencia y existencia/presencia-cuantificación temporal o espacial.

El sujeto puede ser cero o estar representado por una frase 0 cláusula. Suele posponerse al predicado debido al semantismo de la construcción así como a la no animación y no agentividad. Está desempeñado por un infinitivo que alude a algún tipo de evento (vgr. queda remata-lo teito e xa nos imos). En otras ocasiones se trata de una frase cuyos rasgos semánticos son [-animado], [+concreto], en general [+común], [-control].

El complemento resulta obligatorio en las construcciones de sujeto cero. Está representado por un circunstancial concretado con frecuencia en una frase que indica una cuantificación de tiempo o lugar (vgr. quedan dous quilómetros). A veces acompaña algún circunstancial, sobre todo de estructura (para +fn) y (para + cláusula: queda pouco para saírmos), con el papel semántico de fin, loc. temporal (vgr. queda tempo para o outono), locación espacial y causa. Además puede aparecer un dativo y/o compl. indirecto, de referente animado, con el papel semántico de afectado.

La construcción es de estado y no admite se. Se usa en muchas ocasiones referida a tiempo y está en P3 singular o plural. Los valores aspectuales son estativo y atélico.

Otras lenguas como el español presentan esta construcción con presencia o ausencia de dativo y con sujeto pospuesto (vgr. queda tiempo o no nos queda más dinero). El portugués se sirve del predicado faltar (vgr. faltam dois dias para o meu aniversário) y en italiano registramos algo parecido aunque con otras formas verbales (vgr. non ci avanzano più soldi; mi resta ancora un po'di tempo).

\subsection{SUSPENDER Un EXAMEN O UnA MATERIA}

23. O máis seguro é que me queden para setiembre matemáticas, historia e fisica (VEDRA-A Coruña, 16)

24. aínda me han quedar unhas poucas asinaturas pa setiembre porque non fun nada aplicado este ano (VEDRA-A Coruña, 16)

El esquema sintáctico es sujeto-predicado-compl. indirecto y el esquema semántico afectado-acción-beneficiado/perjudicado. 
El sujeto se pospone al predicado debido al semantismo de la construcción con presencia de dativo y en ocasiones a la no animación, no agentividad y no definitud. Sus rasgos semánticos son [-animado], [+concreto], [土común], [-control].

El complemento resulta obligatorio, excepto en aquellas construcciones de significado general y absoluto (vgr. se queda unha soa non pasa nada). Está representado por un pronombre dativo y/o por una frase preposicional de estructura $(a+f n)$, de referente humano, que tiene cierto grado de control en la acción en cuanto que es responsable de ella. En muchas ocasiones funciona de forma opcional algún circunstancial de estructura (para $+\mathrm{fn}$ ), con significado temporal prospectivo (vgr. quedoulle lingua para setembro); también puede acompañar un papel semántico de causa (vgr. quedoulle matemáticas por preguiceiro), exclusión (vgr. quedoulle todo agás matemáticas), condición (vgr. coa túa axuda non lle quedaría matemáticas), concesión (vgr. mesmo coa túa axuda quedaríalle matemáticas)...

La construcción tiene forma activa, con un significado próximo al de la voz media. Se usa en P3 singular o plural y no admite se. Frente a la estructura intransitiva de sujeto inanimado y no agentivo, la transitiva refleja control, agentividad, afección y mayor protagonismo de un sujeto que es animado (vgr. suspendeu matemáticas e historia). Los valores aspectuales prototípicos son dinámico, télico.

Otras lenguas próximas conocen esta estructura, aunque pueden cambiar el predicado, de este modo el español usa quedar o suspender (vgr. me queda una asignatura), el portugués prefiere reprovar o não passar (vgr. não passei em latim) y el italiano emplea bacciare.

\subsection{Coger Algo Para Uno, Apropiarse}

25. temos uns baixos de prezo que son unha ganga. Quedamos con estes para nós e estoutros para os nosos amigos, ... (EBO, 372)

26. volvina facer de novamente e aquela parte pequena pois quedeime eu con ela (GUNTÍN-Lugo, 54)

El esquema sintáctico es sujeto-predicado-compl. prepositivo y el esquema semántico agente-acción-término.

El sujeto se pospone con frecuencia al predicado debido al semantismo de la construcción con presencia de dativo y/o compl. indirecto y a los rasgos de no animación y no agentividad. Sus rasgos semánticos son [+humano], [+concreto], [+común], [+control].

El complemento es obligatorio. Está representado por una frase preposicional de estructura (con $+\mathrm{fn}$ ), pospuesta al predicado en el orden no marcado y con un referente de rasgos semánticos [-animado], [+concreto], que designa aquello que alguien coge para sí. Cuando el complemento alude 
a un objeto mental como nombres o palabras el significado puede variar (vgr. quedei co seu nome). De forma opcional funciona algún circunstancial con el papel semántico sobre todo de loc. espacial o temporal, causa (vgr. nesta habitación quedo eu coa manta polo frío), fin, destinatario, sustitución (vgr. hoxe quedo eu co coche en vez de miña irmá).

La construcción es activa. A veces presenta forma pronominal (vgr. quedeime cos libros/co seu nome), con un clítico que pretende poner de relieve el papel de agente, poseedor y beneficiado del sujeto. También puede admitir se para indicar sujeto indeterminado. Los valores aspectuales prototípicos son dinámico y atélico.

Otras lenguas como el español emplean esta construcción bajo forma pronominal (vgr. me quedé con todos los libros), a veces transitiva (vgr. quédate esa foto; si te gusta el libro quédatelo; me quedé con su nombre). El portugués usa frase preposicional (vgr. gosto desse quadro e fico com ele) o estructuras transitivas (vgr. não guardo os nomes das pessoas). El italiano, a diferencia del gallego, se vale de una estructura pronominal con clítico antepuesto al verbo (vgr. quedeime con todos os libros / mi tenni tuti i libri).

\subsection{TOCAR o CoRRESPONDERLE Algo A Alguien}

27. a ela quedoulle a casa e ó irmau o piso (COVAS-FORCAREIPontevedra, 70)

El esquema sintáctico es sujeto-predicado-compl. indirecto y el esquema semántico afectado-acción-beneficiado/perjudicado.

El sujeto se pospone a menudo al predicado debido al semantismo de la construcción con presencia de dativo y/o compl. indirecto así como a la no animación y no agentividad del sujeto. Sus rasgos semánticos son [-animado], [+concreto], en general [+común], [-control].

El complemento resulta obligatorio. Está representado por un dativo y/o compl. indirecto, en ocasiones por una frase preposicional de estructura (para + fn) (vgr. a casa quedou para o fillo máis vello), con un referente animado que indica el individuo - beneficiado o perjudicado - al que le corresponde algo.

La construcción tiene carácter activo, con un significado próximo al de las estructuras de voz media. No admite se y se usa en la P3 singular o plural. Los valores aspectuales prototípicos son dinámico y atélico.

Otras lenguas como el castellano conocen esta construcción con dativo o con a/para y valor de destinatario/beneficiado (vgr. todos sus bienes (se) quedarán a/para los hijos). El portugués la utiliza con una función de dativo ou con un destinatario (vgr. feitas as partilhas viu que não lhe ficou grande coisa) y en italiano documentamos restare a (vgr. tutti i suoi beni resteranno ai figli). 


\subsection{Alcanzar Una Determinada Consideración Por Algo Que SE Hizo}

28. quedar ben non costa nada (FORCAREI-Pontevedra, 45)

29. quedou de parvo diante de todos (LOUREIRO-COTOBADEPontevedra, 80)

30. quedou por parvo, pero é máis listo ca eles (LOUREIRO-COTOBADEPontevedra, 80)

El esquema sintáctico es sujeto-predicado-predicativo y el esquema semántico portador de estado-estado-modo.

El sujeto suele preceder al predicado y se caracteriza por los rasgos semánticos [+humano], [+concreto], [+común], [-control].

El complemento resulta obligatorio. Puede estar desempeñado por una frase adverbial, una cláusula modal o comparativa introducida por como, coma, una frase preposicional de estructura (de, por + frase adjetiva) con nombres que en muchas ocasiones caracterizan al sujeto negativamente (parvo, badulaque...). Las estructuras con (de +frase adjetiva) pueden adquirir valor comparativo y modal y tienden a usarse para aludir a un momento preciso o corto de tiempo (vgr. quedou de parvo nun momento dado). Las estructuras con (por+frase adjetiva) adquieren preferentemente valores modales, abarcan una mayor dimensión temporal (vgr. quedou por parvo dende un momento dado ata hoxe) y admiten con más facilidad cláusulas de signo contrario como adversativas, concesivas, etc. (comp. quedou por parvo, pero é moi listo / quedou de parvo, pero é moi listo). De manera opcional es posible que funcionen otros circunstanciales con papeles semánticos como locación temporal y espacial, presencia, causa, destinatario (vgr. onte quedamos moi ben con eles dándolles de xantar), condición (vgr. coa túa colaboración quedaría de traballadora), concesión, etc.

La construcción refleja el estado de un individuo, resultado de un evento anterior. Admite se para indicar sujeto indeterminado. Los valores aspectuales son estativo, atélico, télico si nos referimos a un momento preciso y sin duración en el tiempo.

En otras lenguas como el español se emplea sobre todo la estructura (por + frase adjetiva) (vgr. quedar por tonto). El portugués conoce esta estructura (vgr. ficar bem/mal com um amigo) $u$ otras diferentes (vgr. passou por bobo quando perguntou isso). El italiano se vale del verbo passare (vgr. passò per sciocco) o de resultados analógicos como essere considerato + adjetivo, fare brutta figura.

\subsection{En Un Juego Ser El Que Busca A los Otros O El Que No Sigue ReCibiEndo CARTAS}

31. un grupo de rapaces de aquí, un quedaba, o sea dormía e os outros agachábanse (ACIVEIRO-FORCAREI-Pontevedra, 29) 
32. eu quédome (CACHAFEIRO-FORCAREI-Pontevedra, 65)

El esquema sintáctico es sujeto-predicado y el esquema semántico agente-acción.

El sujeto puede situarse en posición posverbal, sobre todo cuando no aparecen complementos (vgr. quedas ti). Sus rasgos semánticos son [+humano], [+concreto], [土común], [+control].

El complemento no resulta obligatorio. A veces funciona un adverbio modalizador o algún circunstancial con distintos papeles semánticos como tiempo y duración, loc. espacial, modo, causa, fin (vgr. quedo eu para que non te piques), sustitución (vgr. quedo eu en vez dela; quédase en vez de seguir), condición (vgr. coa túa axuda non se quedaría), consecuencia (vgr. queda tanto que se enfada).

La construcción es pronominal, de carácter activo. Admite se indicando sujeto indeterminado y poniendo de relieve el papel agentivo del sujeto. Los valores aspectuales prototípicos son dinámico, atélico, en ocasiones iterativo.

Otras lenguas como el español manejan esta construcción (vgr. queda Juan). El portugués se vale de ficar para el contenido de rechazar cartas por tener buena jugada. El italiano puede utilizar predicados diferentes (vgr. tocca a Giovanni).

\subsection{Ponerse QuiEto, no EsPabilarse, CAlmarse}

33. cando despois veu a vaca pa aquí, a nosa comíalle a cadrena á outra, e a outra quedábase e empezáballe Ghesús... (LALÍnPontevedra, 70)

34. parece que o vento se vai quedando (SANTIAGO, 35)

El esquema sintáctico es sujeto-predicado, con un doble esquema semántico agente-acción, fuerza-acción.

El sujeto puede preceder al predicado o seguirlo sobre todo con sujetos animados y cuando el emisor centra su interés en el evento (vgr. quédase o vento). Sus rasgos semánticos son [+animado], [+concreto], [+común], [+control].

El complemento no resulta obligatorio. Puede funcionar un dativo y/o compl. indirecto con el papel semántico de beneficiado o perjudicado, un predicativo representado sobre todo por una frase preposicional y frase adjetiva (vgr. que se quede quieta), y un circunstancial con el papel semántico de modo, causa (vgr. co medo ela quedábase; coa néboa o mar quedouse), fin, condición...

La construcción es activa. Presenta forma pronominal, con un clítico que actúa como formante lexemático del verbo y que contribuye a establecer una oposición de contenido con las demás acepciones nucleadas por este verbo que no lo presentan; el clítico además hace que la acción se centre en 
el sujeto. En ocasiones se transmite una acción en proceso concretada en un esquema experimentante-proceso. Los valores aspectuales prototípicos son dinámico, atélico; en muchos casos inceptivo motivado por el clítico, que contribuye a marcar el comienzo de la acción.

Otras lenguas como el español registran esta estructura (vgr. la furia del viento se fue quedando). El portugués mantiene la construcción pronominal (vgr. seguiram todos e ele ficou-se; o cabalo ficou-se) así como el italiano, que utiliza otros verbos (vgr. la furia del vento andò placandosi; rimanere allibito).

\subsection{Perder El Conocimiento O Morir}

35. o Folión camiña coa man no peito, temeroso de que o corazón se lle quede como un paxariño (MFB, 146)

36. cando se lle corta o nervio simpático o corazón quédase (OCG, 0303-99,4)

El esquema sintáctico es sujeto-predicado y el esquema semántico afectado-acción.

El sujeto puede preceder o seguir al predicado. La posposición obedece sobre todo a la no animación del sujeto y al semantismo de la construcción, por lo regular con dativo (vgr. quedóuselle o corazón). Sus rasgos semánticos son [+animado] y [+ humano], [+ concreto], [-control] o [contro parcial].

El complemento no resulta obligatorio. En ocasiones funciona un dativo o compl. indirecto con el papel semántico de afectado (vgr. quedóuselle o corazón), un predicativo y un circunstancial con el papel semántico sobre todo de modo, causa (vgr. co susto quedouse), condición y consecuencia, loc. espacial o temporal.

La construcción es pronominal, con significado de voz media y un clítico que actúa como formante lexemático del verbo, estableciendo además una oposición de contenido con las restantes acepciones y contribuyendo a centrar la acción en el sujeto. Los valores aspectuales prototípicos son dinámico, télico, puntual. En muchos casos se refleja un valor inceptivo motivado por el clítico, que contribuye a marcar el comienzo de la acción.

Otras lenguas próximas como el español se valen de la misma construcción (vgr. se quedó en el accidente). El portugués mantiene la estructura cambiando el predicado (vgr. meu vizinho faleceu num acidente) al igual que el italiano (vgr. è morto nell' incidente).

\section{CONCLUSIÓN}

Una vez analizadas distintas construcciones prototípicas con quedar, los datos obtenidos nos permiten observar ciertas tendencias y llegar a las conclusiones que a continuación detallamos. 
El esquema sintáctico que más se reitera es el de sujeto-predicado (37\%), en segundo lugar el de sujeto-predicado-compl. prepositivo (21\%), a continuación el de sujeto-predicado-predicativo (16\%) y en menor medida sujeto-predicado-circunstancial, sujeto-predicado-complemento indirecto, predicado-circunstancial. De aquí inferimos que la mayor productividad de los esquemas nucleados por quedar reside en las construcciones monoargumentales de sujeto-predicado y en las biargumentales con preposición.

Los esquemas semánticos que derivan de dichas construcciones son por orden de frecuencia los siguientes:

De un papel: agente-acción, afectado-acción, fuerza-acción, portador de existencia/presencia-existencia/presencia,situadosituación, existencia/presencia-cuantificación.

De dos papeles: agente-acción-término, portador de estado-estadomodo, afectado-acción-beneficiado/perjudicado, afectado-acciónlocación espacial, evento-acción-término, situado-situaciónlocación espacial.

A partir de aquí, es fácil deducir que estas construcciones intransitivas documentadas en nuestro corpus pueden transmitir diferentes contenidos: acciones (57\%), estados propiamente dichos (31.5\%), situaciones (10.5\%) y existencia/presencia (10.5\%). Todo lo cual prueba que quedar no sólo es predicado de construcciones de estado como en principio podría pensarse.

En lo referente al sujeto, las estructuras documentadas pueden funcionar con algún sujeto implícito, explícito, indeterminado o cero. Buena parte de los sujetos se sitúan en posición preverbal o posverbal, esta última determinada por factores como el semantismo, el centro de atención establecido por el emisor, la animación, la voz y la definitud. La distribución entre animados y no animados se establece de un modo más o menos equilibrado, sin embargo los sujetos que manifiestan ausencia de control (57\%) superan a los restantes. La diferencia se acentúa si comparamos los sujetos que refieren entidades concretas (84\%) con los que aluden a entidades abstractas.

En cuanto al complemento, apreciamos una cierta proporción entre construcciones en las que resulta obligatorio y aquellas en las que es opcional. En las primeras suele repetirse el complemento prepositivo introducido por las preposiciones con, de, en, así como el circunstancial, predicativo y complemento indirecto. También es frecuente que acompañe algún otro circunstancial opcional dando cuenta del lugar, tiempo, modo, causa, fin, condición... del evento.

La voz puede ser activa o media. Los valores aspectuales sitúan a estas construcciones a caballo entre la estatividad y la dinamicidad; las que adquieren valor dinámico representan el $62 \%$ y las de valor estativo el $37.5 \%$. Este mismo resultado se repite para las de valor atélico frente a télico. 
Por último, cabe decir que las soluciones ofrecidas por otras lenguas próximas no difieren en exceso de las documentadas para el gallego en lo relativo a estructuras. La mayor parte de las divergencias se encuentran en el terreno de las construcciones pronominales, que unas lenguas admiten y otras como el gallego no tanto, también en ciertas regencias preposicionales, en el orden preverbal o posverbal de algunos sujetos y en la divergencia de predicados verbales.

Como hemos señalado al comienzo, se trata construcciones de una gran diversidad y riqueza, cuya sistematización y estudio puede revelarse de gran utilidad para la lingüística en lo que concierne a la elaboración de gramáticas, diccionares convencionales y de construcciones, contraste de lenguas y enseñanza del gallego como segunda lengua.

Si bien las gramáticas, sobre todo de corte tradicional, acostumbran a incluir estas construcciones nucleadas por quedar en el ámbito de las de estado, es evidente que su dimensión va más allá, comprende la existencia, la situación y la acción, de ahí que estén entre la estatividad y la dinamicidad.

\section{RESUMO}

Este artigo tem como objetivo estudar os principais esquemas do verbo quedar em galego. Baseia-se na investigação realizada no âmbito da nossa tese, trabalho que estuda os esquemas sintático-semânticos visando a elaboração de um dicionário de construções da língua galega. Partimos do conceito de transitividade e, seguidamente, a partir de um quadro teórico baseado na construção, que associa as dimensões semântica, sintáctica e lexical, tentamos estabelecer uma descrição desta língua, também útil para a linguística geral.

Palavras-chave: quedar; esquema sintáctico-semântico; construção; intransitividade.

\section{RÉSUMÉ}

Cet article a pour but d'étudier les principaux schèmes de quedar en Galicien. Il se fonde sur las recherches réalisees dans notre thèse. Travail qui étudie les schèmes sémanticosyntactiques en vue de faire un dictionnaire de constructions de la langue galicienne. Nous partons du concept de intransitivité et ensuite, à partir d'un cadre théorique basé sur la construction, qui associe les dimensions sémantique, syntactique et lexicale, nous essayons d'établir une description de cette langue, utile aussi pour la linguistique général. Mots clés: quedar; schéme sémantico-syntactique; construction; intransitivité. 


\begin{abstract}
The aim of this paper is to analyse quedar schemes in Galician language. The study is based on the research carried out in our doctoral thesis, which was focused on semantic-syntactic schemes in Galician and on the compilation for a dictionary of structures in Galician. With a basis on the concept of intransitivity, we will try to project this semantic concept into the subject of construction in order to describe these new schemes, important for general linguistic as well.

Keywords: quedar; syntactic-semantic scheme; construction; intransitivity.
\end{abstract}

\title{
REFERÊNCIAS
}

1. Corpus

1.1. Lengua escrita

[EBO] CANEIRO, X. C. Ébora. Vigo: Xerais, 2000.

[DEUS] CASARES, Carlos. Deus sentado nun sillón azul. Vigo: Galaxia, 1998.

[MFB] IGLESIAS, Bieito. O mellor francés de Barcelona. Vigo: Galaxia, 1999.

[ESC] RIVAS, Manuel. En salvaxe compaña. 3. ed. Vigo: Xerais, 1995.

[TILG] SANTAMARINA, A. (Dir.). Tesouro informatizado da lingua galega. Universidade de Santiago de Compostela, Instituto da Língua Galega. Publicación electrónica en: < http:/ /www.ti.usc.es/TILG/>

[OCT] XOHÁN CABANA, Darío. O cervo na torre. Vigo: Xerais, 1994.

[MDR] __. Morte de Rei. Vigo: Xerais, 1996.

[OCG] Xornal O Correo Galego de 25/11/1998, 03/03/1999, Santiago de Compostela.

1.2. Lengua oral

FERNÁNDEZ REI, F.; HERMIDA, C. (Eds.) A nosa fala: bloques e áreas lingüísticas do galego. Santiago de Compostela: Consello da Cultura Galega, 1996.

OCHOA, D. A fala do Grove. Traballo de doutoramento inédito. Universidade de Santiago de Compostela, Facultade de Filoloxía, 1994.

SANTAMARINA, A. (Dir.). Tesouro informatizado da lingua galega. Universidade de Santiago de Compostela, Instituto da Lingua Galega. Publicación electrónica en: < http://www.ti.usc.es/ TILG/>, 2004.

SOTO ANDIÓN, X. Gravacións (60 horas). Material inédito transcrito procedente de diferentes puntos de Galicia, Santiago de Compostela, 1993-2000.

VÁZQUEZ-MONXARDín, A. (Coord.). A cultura popular de tradición oral nos centros da terceira idade. Unha experiencia de recollida en Centros de Ourense, Santiago, Tui e Viveiro. Santiago de Compostela: Consello da Cultura Galega, 1992.

VÁzQuEz SOMOZA, X. L. O galego en Zolle (Guntín). Tese de licenciatura inédita. Universidade de Santiago de Compostela, Facultade de Filoloxía, 1986. 
ANDión, X. S. EnTre La Estatividad Y El DinAmismo...

VIDAL, A. Contribución ó estudio do léxico de Loureiro (Cotobade). Tese de licenciatura inédita. Universidade de Santiago de Compostela, Facultade de Filoloxía, 1994.

2. Lingüística (libros, artículos)

ACKEMA, Meter; SCHOORLEMMER, Maaike. The middle construction and the syntaxsemantics interface. Lingua, n. 93, Amsterdam: Elsevier Science B.V, 1994, p. 59-90.

ALARCos, Emilio. Gramática de la lengua española. Madrid: Espasa-Calpe, 1994.

ALEXIADOU, A.; ANAGNOSTOPOULOU, E.; EVERAERT, M. (Eds.). The unaccusativity puzzle: explorations of the syntax-lexicon interface. Oxford: Oxford University Press, 2003.

ÁlVAREZ, R.; REGUEIRA, X. L.; MONTEAGUDO, H. Gramática galega. Vigo: Galaxia, 1986.

ÁlVAREZ, R.; XOVE, X. Gramática da lingua galega. Vigo: Galaxia, 2002.

ARAUJO, Silvia. Le passif dans le système des voix du français et du portugais. In: VEIGA, Alexandre; LONGA, Victor; ANDERSON, JoDee (Eds.). El verbo entre el léxico y la gramática. Lugo: Tris-Tram, 2001. p. 19-30.

BADIA I MARGARIT, A. M. Gramàtica de la llengua catalana. Barcelona: Edicións Proa, 1995.

BALTIN, Mark R. A-movements. In: BALTIN, M.; COLLINS, C. (Eds.). The handbook of contemporary syntactic theory. Oxford: Blackwell, 2001. p. 226-254.

BELLETTI, Adriana. Los inacusativos como asignadores de caso. In: DEMONTE, Violeta; LAGUNILLA, Marina Fernández (Eds.). Sintaxis de las lenguas romances. Madrid: Ediciones el arquero, 1987. p. 167-229.

BERTINETTO, P. M.; DELFITTO, D. Aspect vs. Actionality: why they should be kept apart. In: DAHL, O. (Ed.). Tense and aspect in the languages of Europe. Berlin \& New York: Mouton de Gruyter, 2000. p. 189-226.

. The progressive in Romance, as compared with English. In: DAHL, O. (Ed.). Tense and aspect in the languages of Europe. Berlin \& New York: Mouton de Gruyter, 2000. p. 559-604.

BORER, H. Structuring sense. Oxford: Oxford University Press, 2004.

BRESNAN, J. Lexical-functional syntax. Oxford: Blackwell, 2000.

CANO AGUILAR, Rafael. Estructuras sintácticas transitivas e intransitivas en el español actual. Madrid: Gredos, 1987.

CHOMSKY, Noam. Aspectos de la teoría de la sintaxis. Barcelona: Gedisa, 1999.

COMRIE, Bernard. Universales del lenguaje y tipología lingüística. Madrid: Gredos, 1989.

COSTA, Xoán Xosé; GonZÁlEZ, Anxo\&Morán; CÉSAR\&RÁBADE, Xoán Carlos. Nova gramática para a aprendizaxe da língua. A Coruña: Vía Láctea, 1989.

CREGO, María Victorina. El complemento locativo en español. Los verbos de movimiento y su combinatoria sintáctico-semántica, Lalia, n. 12, Santiago de Compostela: Universidade de Santiago de Compostela, 2000.

CROFT, W. Radical Construction Grammar. New York: Oxford University Press, 2001.

DALRYMPLE, M. (Ed.). Semantics and Syntax in Lexical Functional Grammar. The Resource Logic Approach. Cambridge: MIT Press, 1999.

DIK, Simon C. The theory of functional grammar. 2. ed. Berlín: Mouton de Gruyter, 1997. 
DIMITROVA-VULCHANOVA, Mila. Verbs semantics, diathesis and aspect. München: Lincom Europa, 1999.

DIXON, R. M. W.; AIKHENVALD, A. Y. Changing valency. Case studies in transitivity. Cambridge: Cambridge University Press, 2000.

ESCANDELL, M. V. Introducción a la pragmática. Barcelona: Ariel, 1999.

FABER, P. B.; MAIRAL, R. Constructing a lexicon of English verbs. Berlin/New York: Mouton de Gruyter, 1999.

FARIA, Isabel Hub et al. Introdução à Lingüística Geral e Portuguesa. Lisboa: Caminho, 1996.

FREIXEIRO, Xosé Ramón. Gramática da lingua galega II. Morfosintaxe. Vigo: A Nosa Terra, 2000.

GIVON, T. Syntax II. A functional typological introduction. Amsterdam: John Benjamins, 1990.

GOLDBERG, Adele E. Constructions. A construction grammar approach to argument structure. Chicago: Chicago University Press, 1995.

n. $7,5,2003$.

Constructions: a new theoretical approach to language. Trends in cognitive science,

GUTIÉRREZ ORDÓÑÉZ, S. Introducción a la semántica funcional. Madrid: Síntesis, 1996. . La oración y sus funciones. Madrid: Arco/Libros, 1997.

HALE, Kenneth; KEYSER, Samuel J.. Prolegomenon to a theory of argument structure. Cambridge \& Massachusetts: The MIT Press, 2002.

HALLIDAY, Michael Alexander Kirkwood. An introduction to Functional Grammar. London: Arnold, 1994.

HALLIDAY, Michael Alexander Kirkwood; MATHIESSEN, Christian. An Introduction to Functional Grammar. London: Arnold, 2004.

HERNANZ, María Luisa; BRUCART, José María. La sintaxis (1). Barcelona: Crítica, 1987.

HOPPER, P. J.; THOMPSON, S. A. Transitivity in grammar and discourse. Language, n. 56/ 2, USA: Linguistic Society of America, p. 251-299, 1980.

JACKENDOFF, Ray. Semantic structures. Cambridge \& Massachussets: The MIT Press, 1990.

KAY, P. Words and the grammar of context. Stanford, California: CSLI, 1997.

KIBRIK, A. E. Beyond subject and object: toward a comprehensive relational typology. Linguistic Typology, n. 1-3, p. 279-346, 1997.

LAMIROY, Beatrice. Léxico y gramática del español. Estructuras verbales de espacio y tiempo. Barcelona: Anthropos, 1991.

LANGACKER, Ronald W. Cognitive grammar. In: DROSTE, F.; JOSEPH, J., (Eds.). Linguistic theory and grammatical description. Amsterdam: John Benjamins, 1991. p. 275-306.

LASNIK, H. Syntactic structures revisited. Cambridge/Massachusetts: The MIT Press, 2000.

LAZARD, Gilbert. Definition des actants dans les langues européennes. In: FEUILLET, J. (Eds.). Actance et valence dans les langues de l'Europe. Berlin \& New York: Mouton de Gruyter, 1998. p. 11-146.

. Transitivity Revisited as an Example of a More Strict Approach in Typological Research. Folia Lingüistica, n. XXXVI/3-4. Berlin: Mouton de Gruyter, p. 141-190, 2002. 
ANDión, X. S. Entre La Estatividad Y El Dinamismo...

LEECH, G. N. Principios de pragmática. Logroño: Universidad de La Rioja, 1998.

LEVIN, B.; RAPPAPORT, M. Unaccusativity. At the syntax-lexical semantics interface, Cambridge: MIT press, 1995.

LÓPEZ GARCÍA, A. Gramática del español II. La oración simple. Madrid: Arco/Libros, 1996.

LYONS, John. Introducción al lenguaje y a la lingüística. Barcelona: Teide, 1993.

. Semántica lingüística. Barcelona: Paidós, 1997.

MARTINET, Andrée. Función y dinámica de las lenguas. Madrid: Gredos, 1993.

MATEUS, Maria Helena Mira; BRITO, Ana Maria; DUARTE, Ines; FARIA, Isabel Hub. Gramática da lingua portuguesa. Lisboa: Caminho, 2003.

MIGUEL, Elena De. El aspecto léxico. In: BOSQUE, Ignacio; DEMONTE, Violeta (Eds.). Gramática descriptiva de la lengua española, 2. Madrid: Espasa-Calpe, 1999. p. 29773060.

MORENO CABRERA, Juan Carlos. Introducción a la lingüística. Enfoque teórico y universalista. Madrid: Síntesis, 1997.

Semántica y gramática. Sucesos, papeles semánticos y relaciones sintácticas. Madrid: Machado libros, 2003.

PERLMUTTER, D. J. Relational grammar. In: MORAVCSIK, E.; WIRTH, E. (Ed.). Syntax and semantics 13: current approaches to syntax. New York: Academic Press, 1980. p. 195-229.

PRIMUS, Beatrice. Cases and Thematic roles. Tübingen: Niemeyer, 1999.

PUSTEJOVSKY, J. The generative lexicon. Cambridge \& Massachusetts: The MIT Press, 1998.

RITTEN, E.; ROSEN, S. T. Event structure and ergativity. In: PUSTEJOVSKY, J.; TENNY, C. (Eds.). Events as grammatical objects. Stanford: CSLI, 2000. p. 187-237.

ROTHSTEIN, S. Structuring Events. Oxford: Blackwell, 2004.

SÁNCHEZ LÓPEZ, C. (Ed.). Las construcciones con se. Madrid: Visor, 2002.

SCHACK RASMUSSEN, L. Los aspectos metalexicográficos de un diccionario semántico. Reflexiones en torno a un diccionario semántico de los verbos españoles. In: WOTJAK, Gerd. Estudios de lexicografía y metalexicografia del español. Tübingen: Max Niemeyer Verlag, 1992.

SMITH, C. The parameter of aspect. Dordrecht: Kluwer, 1997.

SOTO ANDIÓN, X. Construcións intransitivas de actitude e conduta en galego. Vox Romanica, Tübingen und Basel: A. Francke Verlag, p. 171-202, 2005.

. O (macro)papel semántico de experimentante: análise descritiva-contrastiva. In: MOURON, Cristina; MORALEJO, Teresa (Eds.). Studies in Contrastive Linguistics. Universidade de Santiago de Compostela: Servizo de Publicacións, 2005. p. 961-971.

Parámetros de base semántica para a descrición e análise de construcións intransitivas en galego, Estudis Romànics, n. XXVIII. Barcelona: Institut d'Estudis Catalans, p. 29-47, 2006.

TESNIÈRE, Lucien. Éléments de syntaxe structurale. 2. ed. Paris: Klincksieck. 1969.

. Elementos de sintaxis estructural. Madrid: Gredos, 1994.

THIEROFF, R. On the areal distribution of tense-aspect categories in Europe. In: DAHL, O. (Ed.). Tense and aspect in the languages of Europe. Berlin/New York: Mouton de Gruyter, 2000. p. 265-305. 
VAN VALIN, Robert D. J. R.; LAPOLLA, Randy. Syntax. Structure, Meaning and Function. Cambridge: Cambridge University Press, 1997.

VAN HOUT, A. Projections based on event structure. In: EVERAERT, M. et al. (Ed.). Lexical specification and insertion. Amsterdam: John Benjamins, 2002. p. 397-422.

VENDLER, Z. Facts and events. In: Linguistics in philosophy. Ithaca: Cornell University Press, 1967. p. 122-146.

VILELA, Mário. Gramática da língua portuguesa. Coimbra: Almedina, 1999.

ZANUTTINI, Rafaella. Negation and Clausal Structure. A Comparative Study of Romance Languages. New York\&Oxford: Oxford University Press, 1997.

Submetido em: 25/01/2008.

Aceito em: 31/03/2009. 